Philadelphia College of Osteopathic Medicine DigitalCommons@PCOM

PCOM Scholarly Papers

$7-30-2018$

\title{
Demographic, Clinical, and Behavioral Determinants of 7-Year Weight Change Trajectories in Roux-en-Y Gastric Bypass Patients.
}

Michelle R. Lent

Philadelphia College of Osteopathic Medicine, michellele@pcom.edu

Yirui Hu

Peter N Benotti

Anthony T Petrick

G Craig Wood

See next page for additional authors

Follow this and additional works at: https://digitalcommons.pcom.edu/scholarly_papers

Part of the Medicine and Health Sciences Commons

\section{Recommended Citation}

Lent, Michelle R.; Hu, Yirui; Benotti, Peter N; Petrick, Anthony T; Wood, G Craig; Still, Christopher D; and Kirchner, H Lester, "Demographic, Clinical, and Behavioral Determinants of 7-Year Weight Change Trajectories in Roux-en-Y Gastric Bypass Patients." (2018). PCOM Scholarly Papers. 1952.

https://digitalcommons.pcom.edu/scholarly_papers/1952

This Article is brought to you for free and open access by DigitalCommons@PCOM. It has been accepted for inclusion in PCOM Scholarly Papers by an authorized administrator of DigitalCommons@PCOM. For more information, please contact library@pcom.edu. 
Authors

Michelle R. Lent, Yirui Hu, Peter N Benotti, Anthony T Petrick, G Craig Wood, Christopher D Still, and H Lester Kirchner 
Original article

\section{Demographic, clinical, and behavioral determinants of 7-year weight change trajectories in Roux-en-Y gastric bypass patients}

Michelle R. Lent, Ph.D. ${ }^{a, b, *}$, Yirui Hu, Ph.D. ${ }^{c}$, Peter N. Benotti, M.D. ${ }^{a}$, Anthony T. Petrick, M.D. ${ }^{a}$, G. Craig Wood, M.S. ${ }^{a}$, Christopher D. Still, D.O. ${ }^{a}$, H. Lester Kirchner, Ph.D. ${ }^{c}$

${ }^{a}$ Geisinger Clinic Obesity Institute, Danville, Pennsylvania

${ }^{b}$ Philadelphia College of Osteopathic Medicine (PCOM) Department of Psychology, Philadelphia, Pennsylvania

${ }^{c}$ Geisinger Department of Biomedical and Translational Informatics, Danville, Pennsylvania

Received 12 June 2018; accepted 22 July 2018; Available online xxx

Abstract

\begin{abstract}
Background:
Objectives: This study evaluated the weight trajectories of Roux-en-Y gastric bypass (RYGB) patients and identified the distinct clinical, behavioral, and demographic features of patients by trajectory.

Setting: Data from 2918 RYGB patients from a comprehensive medical center between January 2004 and November 2016 were included.

Methods: This retrospective, observational study used data for RYGB patients up to 7 years postsurgery. Group-based trajectory models were fitted for percentage weight change. Variables evaluated by trajectory included age, sex, diagnoses, medications, smoking, presurgical body mass index, preoperative weight loss, and early postoperative weight loss.

Results: Of 3215 possible patients, 2918 (90.8\%) were included (mean age $=46.2 \pm 11.2 \mathrm{yr}$, body mass index $=46.9 \pm 7.9 \mathrm{~kg} / \mathrm{m}^{2}$ at the time of surgery). Three weight change trajectories were identified (above average, average, and below average). Mean percentage weight change at the nadir for the above average group was $-42.85 \% \pm 5.7 \%$ compared with $-31.57 \% \pm 5.0 \%$ in the average group and $-22.74 \% \pm 5.7 \%$ in the below average group. Compared with the above average group, the below average group was more likely to be male (odds ratio $[\mathrm{OR}]=2.40$, $P<.0001$ ) and have diabetes (noninsulin users, $\mathrm{OR}=2.08, P<.0001$ ), but less likely to have a smoking history $(\mathrm{OR}=.62, P=.0007)$ or take sleep medications $(\mathrm{OR}=.50, P=.005)$. Below average group patients had a lower BMI at the time of surgery $(\mathrm{OR}=.96, P<.0001)$. Lower initial weight loss postsurgery was associated with a greater chance of a poorer weight outcomes $(\mathrm{OR}=1.64, P<.0001)$.

Conclusion: Select clinical, demographic, and behavioral factors may increase or decrease the chance for better weight loss after RYGB. (Surg Obes Relat Dis 2018;xxx:xxx-xxx.) (C) 2018

American Society for Bariatric Surgery. Published by Elsevier Inc. All rights reserved.
\end{abstract}

Roux-en-Y Gastric bypass; Weight loss trajectories; Predictors
For many patients with obesity, weight loss surgery conveys durable benefits that span improvements in physi-
cal and mental health, longevity, and quality of life [1veys durable benefits that span improvements in physi-
cal and mental health, longevity, and quality of life [1-

E-mail address: michellele@pcom.edu (M.R. Lent).

\footnotetext{
This project was funded, in part, under a grant with the Pennsylvania Department of Health (\#SAP 4100070267). The funders had no role in the study design, data collection, or analysis or preparation of this manuscript.

*Correspondence: Michelle R. Lent, Associate Professor, PCOM 4190 City Avenue, Rowland Hall 532 a, Philadelphia, PA 19131.
} 
4 6]. However, weight change trajectories after surgery are 5 heterogeneous [1]. In 2013, Courcoulas et al. [1] mod6 eled weight change trajectories of surgery patients through 3 years postoperatively and found that approximately $23 \%$ of Roux-en-Y gastric bypass (RYGB) patients did not achieve or sustain $>25 \%$ total weight loss.

In the era of precision medicine [7], better understanding the demographic and clinical features of weight loss surgery patients who experience poorer outcomes would help to guide clinical care. To date, body mass index (BMI) at the time of surgery and age are consistently associated with weight change postoperatively [8-12]. Certain personality disorders or traits, eating pathology and psychiatric disorders, diabetes status, and preoperative weight loss may also relate to postoperative weight loss, though findings are less consistent regarding these relationships [8,9,13-17]. Wood and colleagues [16] found preoperative insulin use, history of smoking, and a high number of prescribed medications to relate to better long-term weight loss, while hyperlipidemia was associated with poorer outcomes. Finally, early postoperative weight loss (initial 3-6 mo) is associated with greater weight loss 2 years after RYGB [18].

This study's objective was to evaluate the determinants of weight change trajectories in a cohort of RYGB patients followed for 7 years postsurgery. Specifically, this study aimed to (1) replicate weight loss trajectory modeling conducted previously [1] but for a longer timeframe and (2) compare the demographic, behavioral, and clinical factors associated with the weight-change trajectories, including preoperative and early postoperative weight loss, diagnoses, and medication use.

\section{Methods}

\section{Participants}

38 De-identified electronic health record (EHR) data were 39 obtained for patients who completed weight loss surgery 40 from January 2004 to November 2016 at a large, ru$41 \mathrm{ral}$, comprehensive medical center. Inclusion criteria were 42 as follows: (1) completion of primary RYGB, and (2) 43 weight data available in the EHR preoperatively and post44 operatively (up to year 7). Patients who were $<1$ year 45 postsurgery were excluded. The preoperative program for 46 weight loss surgery involves a 6- to 12 -month multidisci47 plinary curriculum with the goal of $10 \%$ weight loss [19]. 48 Postoperatively, patients are scheduled for follow-up visits 491 and 2 weeks after surgery; 2, 5, 8, and 12 months; and 50 yearly thereafter.

\section{Outcome measures}

52 The primary study outcome was the percentage of ini53 tial weight change [1], measured longitudinally through
7 years. Weights were collected from the EHR from all 54 encounters across the health system.

Demographic variables included patients' age, sex, and race. Clinical variables collected at the time of surgery were diagnoses (i.e., mood disorders, osteoarthritis, diabetes, nondependent drug use, hypertension, sleep disorders, back or soft tissue disorders, fibrosis, and dyslipidemia as documented by International Classification of Disease code), use of certain medications and total medications prescribed, and surgical BMI.

Behavioral factors included history of smoking, presurgical weight loss (time of initial consult to day of surgery), and early postoperative weight change (percentage weight change from day of surgery through postsurgery month $6)$.

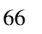
67

\section{Statistical analyses}

Descriptive statistics characterized the cohort at the time of surgery (mean and standard deviation for continuous variables and frequency for categorical variables).

To account for heterogeneity of postsurgery weight change patterns, group-based trajectory models (GBTM) [20] with time as a polynomial trend (6 mo postsurgery through up to $7 \mathrm{yr}$ postsurgery) were fitted for the percentage weight change from baseline. Given a minimum of $1 \%$ sample inclusion per trajectory [1], Bayesian criterion determined the best model fit. Percentage weight change up to 7 years postsurgery was plotted from postoperative month 6 for each trajectory. To identify factors associated with group membership, preoperative factors and weight change within 6 months postsurgery were linked to the trajectories by simultaneously fitting a multinomial logistic regression within the GBTM.

Given the large number of baseline covariates, a selection procedure was implemented. From the initial GBTM, each patient was assigned the trajectory corresponding to the highest membership probability. A multinomial logistic regression model was fit using stepwise selection, erring on the side of including more variables in the model. Finally, the reduced set of baseline covariates was entered into the GBTM to fit the final model. Model results are reported using odds ratios (ORs) and $95 \%$ confidence intervals (CIs).

The trajectory assignment was repeated for the final model to permit characterizing the trajectory patterns. Analysis of variance was conducted to test the differences in continuous variables, and Pearson $\chi^{2}$ tests were performed to test the independence of categorical variables in the 3 subgroups. Analyses were performed using SAS 9.4. Results were considered significant at $P<.05$. The health system's institutional review board approved this study. 78 79 80

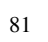
, 8 84 
Table 1

Number of Roux-en-Y gastric bypass patients with weight data at each postsurgery year $(\mathrm{N}=2918)$.

\begin{tabular}{lllll}
\hline $\begin{array}{l}\text { Postsurgery } \\
\text { year }\end{array}$ & Frequency & $\begin{array}{l}\text { Total } \\
\text { eligible }\end{array}$ & $\begin{array}{l}\text { Percent } \\
(\mathrm{N})\end{array}$ & $\begin{array}{l}\text { Weight } \\
\text { change } \%^{*}\end{array}$ \\
\hline 1 & 2399 & 2918 & 82.2 & $-31.1(8.1)$ \\
2 & 1738 & 2835 & 61.3 & $-31.2(10.5)$ \\
3 & 1714 & 2519 & 68.0 & $-28.7(10.8)$ \\
4 & 1455 & 2140 & 68.0 & $-26.9(11.2)$ \\
5 & 1244 & 1778 & 70.0 & $-25.5(11.6)$ \\
6 & 1049 & 1435 & 73.1 & $-24.6(11.8)$ \\
7 & 586 & 1019 & 57.5 & $-24.5(12.0)$ \\
\hline
\end{tabular}

*Weight change $\%$ from time of surgery.

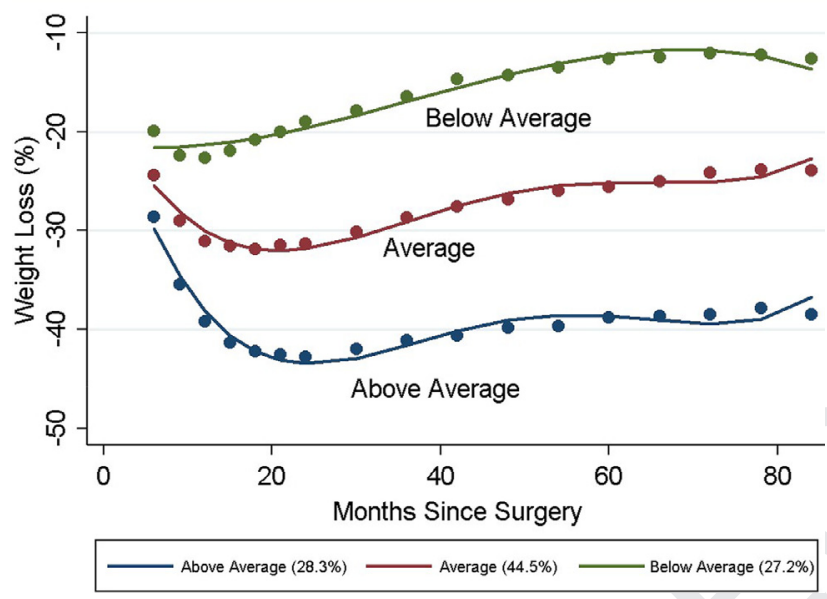

Fig. 1. Weight change trajectories in Roux-en-Y gastric bypass patients $(\mathrm{N}=2918)$ up to 7 years postoperatively.

\section{Results}

106 Of 3215 possible eligible RYGB patients, 2918 patients $107(90.8 \%)$ had a weight in the EHR at postsurgery years 1 108 through 7. Data available for analyses at each postoperative 109 year are in Table 1 . At the time of surgery, patients were a 110 mean age of $46.2 \pm 11.2$ years with a mean BMI of 46.9 $111 \pm 7.9 \mathrm{~kg} / \mathrm{m}^{2}$.

\section{Weight change trajectories}

Q7

113 Through evaluation of the BIC criterion and visual fit, 3 114 weight-change trajectories were best modeled with 2 quar115 tic and 1 cubic polynomials (Fig. 1). Group $1 \quad(n=818$, $11628 \%$ ) achieved a weight loss nadir of $-42.85 \% \pm 5.68 \%$ 117 at 24 months postsurgery and $-38.50 \% \pm 7.37 \%$ weight 118 loss at postsurgery year 7 ("above average" group). Group 1192 ( $\mathrm{n}=1307,45 \%$, "average" group) achieved a weight loss 120 nadir of $-31.57 \% \pm 5.00 \%$ at 15 months postsurgery and $121-24.06 \% \pm 7.48 \%$ weight change at postsurgery year 7 . 122 Group $3(\mathrm{n}=793,27 \%$, "below average" group) achieved 123 a weight loss nadir of $-22.74 \% \pm 5.66 \%$ at 12 months 124 postsurgery and $-12.67 \% \pm 8.41 \%$ weight loss at post125 surgery year 7.
Mean percentage weight change for the above average 126 group was $-28.43 \% \pm 5.69 \% ;-24.38 \% \pm 4.37 \%$ in the 127 average group, and $-20.13 \% \pm 4.33 \%$ in the below aver- 128 age group.

\section{Demographic characteristics}

Characteristics by trajectory group are in Table 2. Com- 131 pared with the above average group (Table 3), patients 132 in the below average group were more likely to be male 133 $(\mathrm{OR}=2.40, \mathrm{CI}=1.63-3.51, P<.001)$.

\section{Clinical characteristics}

Compared with the above average group, the below 136 average group (Table 3) had lower BMI at the time of 137 surgery $(\mathrm{OR}=.91, \mathrm{CI}=.90-.93, P<.0001)$. Below aver- 138 age group patients were less likely to take sleep medica- 139 tions $(\mathrm{OR}=.51, \mathrm{CI}=.32-.81, P=.005)$ but more likely to 140 have diabetes (noninsulin users, $\mathrm{OR}=2.08,1.46-2.96, P{ }_{141}$ $<.0001)$.

No significant differences between trajectory groups 143 were identified regarding number of medications or diag- 144 noses of fibrosis, osteoarthritis, iron deficiency, sleep disor- 145 ders, back or soft tissue disorders, or psychiatric disorders 146 at the time of surgery $(P>.05$, Table 3$)$.

\section{Behavioral factors}

148

Below average group patients were less likely to smoke 149 $(\mathrm{OR}=.62, \mathrm{CI}=.47-.81, \quad P=.0007)$. Mean preoperative 150 and early postoperative weight changes by group are in 151 Table 2. No significant relationship was found between pre- 152 operative weight change and postoperative weight trajec- 153 tories $(P>.05)$. Smaller weight loss in the first 6 months 154 postsurgery was associated with greater chance of a poorer 155 long-term weight outcome $(\mathrm{OR}=1.64, \mathrm{CI}=1.57-1.70,156$ $P<.0001)$.

\section{Discussion}

158

This study identified 3 distinct weight loss trajectories 159 up to 7 years after RYGB. Our modeling resulted in fewer 160 trajectories compared with a previous study that identified 161 5 trajectories [1], which is likely due to differing study 162 durations, the data used, and statistical approaches. While 163 almost half of our RYGB patients sustained a successful 164 amount of weight at postoperative year 7 (25-30\%), the 165 remaining half equally either sustained an above average 166 amount $(\geq 40 \%)$ or a below average amount $(\leq 20 \%)$ after 167 reaching their weight loss nadir.

Comparison of the demographic and clinical character- 169 istics of the 2 most divergent weight loss outcomes (above 170 average versus below average) led to the identification of 171 several distinguishing characteristics. First, males were $>2172$ 
Table 2

Demographic, clinical, and behavioral factors of Roux-en-Y gastric bypass patients by weight change trajectory group $(\mathrm{N}=2918)^{*}$.

\begin{tabular}{lllll}
\hline & $\begin{array}{l}\text { Below average } \\
(\mathrm{n}=793)\end{array}$ & $\begin{array}{l}\text { Average } \\
(\mathrm{n}=1307)\end{array}$ & $\begin{array}{l}\text { Above average } \\
(\mathrm{n}=818)\end{array}$ & $P$ value \\
\hline Male sex, n (\%) & $176(22.2)$ & $260(19.9)$ & $133(16.3)$ & $<.01$ \\
Smoking history, $\mathrm{n}(\%)$ & $391(49.3)$ & $646(49.4)$ & $470(57.5)$ & $<.001$ \\
Age at surgery, yr, mean (SD) & $48.7(11.0)$ & $45.5(11.0)$ & $43.2(10.9)$ & $<0.0001$ \\
BMI at surgery, kg/m ${ }^{2}$, mean (SD) & $46.4(7.9)$ & $46.4(7.8)$ & $48.1(7.9)$ & $<.0001$ \\
Presurgical BMI change, kg/m ${ }^{2}$, mean (SD) & $-5.6(5.1)$ & $-4.8(5.3)$ & $-3.8(5.7)$ & $<.0001$ \\
Early postoperative weight change (0-6 mo \%), & $-20.1(4.3)$ & $-24.4(4.4)$ & $-28.4(5.1)$ & $<.0001$ \\
mean (SD) & & & & $<.001$ \\
Nondependent drug/alcohol use N (\%) & $31(3.9)$ & $76(5.8)$ & $69(8.4)$ & $<.001$ \\
Diabetes & $373(47.0 \%)$ & $480(36.7 \%)$ & $223(27.3 \%)$ & $<.001$ \\
Hypertension & $443(55.9 \%)$ & $654(50.0 \%)$ & $344(42.0 \%)$ & $<.001$ \\
Dyslipidemia & $362(45.7 \%)$ & $538(41.2 \%)$ & $285(34.8 \%)$ & .52 \\
Fibrosis, n (\%) & $223(28.1)$ & $339(25.9)$ & $214(26.3)$ & .54 \\
Iron deficiency, $\mathrm{n}(\%)$ & $107(13.5)$ & $170(13.0)$ & $96(11.7)$ & 0.25 \\
Osteoarthrosis and allied disorders & $170(21.4 \%)$ & $305(23.3 \%)$ & $204(24.9 \%)$ & .15 \\
Disorders of the back & $63(7.9 \%)$ & $136(10.4 \%)$ & $84(10.3 \%)$ & .51 \\
Soft tissue disorders & $42(5.3 \%)$ & $71(5.4 \%)$ & $53(6.5 \%)$ & .19 \\
Depression & $238(30.0 \%)$ & $351(26.9 \%)$ & $244(29.8 \%)$ & .91 \\
Sleep disorders & $140(17.7 \%)$ & $224(17.1 \%)$ & $138(16.9 \%)$ & $<.001$ \\
Any diabetes medication use & $222(28.0 \%)$ & $244(18.7 \%)$ & $122(14.9 \%)$ & $<.001$ \\
Insulin use & $145(18.3 \%)$ & $213(16.3 \%)$ & $92(28.0 \%)$ & $<.01$ \\
Bupropion & $69(8.7 \%)$ & $108(8.3 \%)$ & $100(12.2 \%)$ & .11 \\
Total medications $(>12)$ & $377(47.5 \%)$ & $588(45.0 \%)$ & $346(42.3 \%)$ & \\
\hline
\end{tabular}

$\mathrm{SD}=$ standard deviation; $\mathrm{BMI}=$ body mass index.

* At time of surgery unless otherwise noted.

${ }^{\dagger}$ Analysis of variance for continuous variables; $\chi^{2}$ test for categoric variables.

Table 3

Demographic, clinical, and behavioral factors associated with weight trajectory membership $(\mathrm{N}=2918)$.

\begin{tabular}{lllll}
\hline & $\begin{array}{l}\text { Below average versus } \\
\text { above average OR } \\
(95 \% \text { CI })\end{array}$ & $P$ value & $\begin{array}{l}\text { Average versus above } \\
\text { average OR (95\% CI) }\end{array}$ & $P$ value \\
\hline Age, yr & $1.00(.99-1.02)$ & .81 & $1.01(.99-1.02)$ & .26 \\
Sex, male & $2.40(1.64-3.51)$ & $<.0001$ & $.71(.57-.89)$ & .0003 \\
Smoking history, yes & $.62(.47-.82)$ & .0007 & $.71(.57-.89)$ & .003 \\
BMI, kg/m ${ }^{2}$ (time of surgery) & $.91(.90-.93)$ & $<.0001$ & $.94(.93-.95)$ & $<.0001$ \\
Early postoperative weight & $1.64(1.57-1.70)$ & $<.0001$ & $1.25(1.21-1.28)$ & $<.0001$ \\
change (0-6 mo, \%) & & & & .08 \\
Depressive disorder & $.98(.72-1.33)$ & .89 & $.80(.63-1.03)$ & .43 \\
Sleep medication & $.50(0.31-.80)$ & .005 & $.86(.61-1.23)$ & .02 \\
Diabetes, no insulin & $2.08(1.46-2.96)$ & $<.0001$ & $1.44(1.08-1.94)$ & .17 \\
Diabetes, insulin & $1.23(.81-1.88)$ & .33 & $1.28(.90-1.81)$ & \\
\hline
\end{tabular}

$\mathrm{OR}=$ odds ratio $\mathrm{CI}=$ confidence interval; $\mathrm{BMI}=$ body mass index.

Adjusted results from group-based trajectory modeling.

* Inverse relationship given that lower weight loss is associated with risk of below average group.

173 times as likely to have below average outcomes. Though 174 we had fewer males than females in our cohort, similar 175 findings were reported in male gastric banding patients 176 over aged $\geq 50$ years [12]. Unlike previous studies, we did 177 not find older age to be a risk factor for poorer weight loss $178[8,10,16]$, which may relate to the long study timeframe. 179 Future studies could evaluate sex and age in patients who 180 undergo sleeve gastrectomy, a procedure that is rising in 181 popularity.

182 Second, patients with a higher BMI at the time of 183 surgery were more likely to experience better BMI change over the study period, which mirrors the findings of several 184 previous studies [21,22]. Higher BMI may be associated 185 with greater co-morbidity, which may provide greater mo- 186 tivation to adhere to the postoperative diet and lifestyle in 187 the long term. However, other studies reported higher BMI 188 to predict poorer weight loss, but these studies primar- 189 ily used percentage excess weight loss to evaluate weight 190 change, which is influenced by initial BMI [8,16,21]. $\quad 191$

Third, the use of certain medications was associated 192 with weight change. Patients with diabetes who did not 193 use insulin were $>2$ times as likely to experience below 194 
195 average weight loss. Notably, insulin use appeared to atten196 uate this risk. This finding adds to the mixed findings on 197 diabetes and long-term weight change after RYGB $[8,16]$. 198 Patients using sleep medications were 50\% less likely to 199 experience poor trajectories. Patients using sleep medica200 tions may be less likely to rise during the night, providing 201 fewer opportunities for calorie consumption. Additionally, 202 these patients could be more rested, providing greater mo203 tivation to engage in healthy eating and lifestyle behav204 iors.

Several behavioral factors were evaluated in regard to 206 weight outcomes, including preoperative and early postop-

erative weight loss and smoking history. We did not find a relationship between preoperative weight change and postoperative weight outcomes. A previous prospective, randomized trial found patients in a preoperative program with the goal of $10 \%$ weight loss achieved greater percentage excess weight loss at 3 months postsurgery compared with controls with no preoperative weight loss expectation [23]. Physician-supervised preoperative weight loss is strongly recommended, if not required, as a prerequisite to surgery in many programs [24]; however, our findings do not support the clinical relevance of this recommendation as it relates to a patient's ability and readiness to implement behavior change. Additional prospective, randomized studies are needed to investigate the direction of the potential relationship between preoperative weight loss and long-term outcomes.

In our study, greater weight loss within the initial 6 postoperative months decreased the likelihood of poorer weight outcomes. Manning et al. [18] also found initial weight loss velocity after RYGB to predict better weight loss. Collectively, our findings suggest that clinically, this initial period of rapid weight loss may be a target for future interventions. While diet during the first 3 postoperative months is largely dictated by the staged dietary progression [25], patients can exert more choice regarding level of adherence to the recommended long-term diet during postoperative months 3 to 6 . Future studies could evaluate the impact of additional behavioral support during this critical weight loss time on dietary adherence and long-term weight outcomes. Finally, patients with a history of smoking were less likely to have below average long-term weight loss $(38 \%)$. A history of smoking may be protective in that patients may be able to apply the experience and skills gained to achieve smoking cessation to behavior change for long-term weight reduction.

Our study had several strengths, including the long timeframe for some patients, the inclusion of all available weight data from the EHR, and the wide range of demographic, behavioral, and clinical factors explored in relation to weight trajectories. Our study was limited, however, by the retrospective design, homogeneity of our cohort, fewer patients for inclusion at the later postoperative years, and the inclusion of only 1 procedure type (RYGB).

\section{Conclusion}

In summary, certain RYGB patients may be at risk for 251 less robust long-weight loss. These patients, however, still 25 lose clinically meaningful amounts of weight and may ex- 253 perience the other well-documented benefits of surgery, 254 such as improvements in co-morbid conditions and qual- 255 ity of life [3-5,26]. Study findings can help to inform 256 patient-provider discussions surrounding postoperative ex- 257 pectations after RYGB and better guide clinical care.

\section{Disclosures}

The authors have no commercial associations that might 260 be a conflict of interest in relation to this article.

261

\section{References}

[1] Courcoulas AP, Christian NJ, Belle SH, et al. Weight change and 263 health outcomes at 3 years after bariatric surgery among individuals 264 with severe obesity. JAMA 2013;310(22):2416-25.

[2] Courcoulas AP, Yanovski SZ, Bonds D, et al. Long-term outcomes 266 of bariatric surgery: a National Institutes of Health symposium. 267 JAMA Surg 2014;149(12):1323-9.

[3] Adams TD, Davidson LE, Litwin SE, et al. Health benefits of gastric 269 bypass surgery after 6 years. JAMA 2012;308(11):1122-31. 270

[4] de Zwaan M, Lancaster KL, Mitchell JE, et al. Health-related quality 271 of life in morbidly obese patients: effect of gastric bypass surgery. 272 Obes Surg 2002;12(6):773-80.

[5] Strain GW, Kolotkin RL, Dakin GF, et al. The effects of weight 274 loss after bariatric surgery on health-related quality of life and de- 275 pression. Nutr Diabetes 2014;4:e132.

[6] Arterburn DE, Olsen MK, Smith VA, et al. Association between 277 bariatric surgery and long-term survival. JAMA 2015;313(1):62-70. 278

[7] Ashley EA. The precision medicine initiative: a new national effort. 279 JAMA 2015;313(21):2119-20.

[8] Still CD, Wood GC, Chu X, et al. Clinical factors associated with 281 weight loss outcomes after Roux-en-Y gastric bypass surgery. Obe- 282 sity (Silver Spring) 2014;22(3):888-94.

[9] Livhits M, Mercado C, Yermilov I, et al. Preoperative predictors 284 of weight loss following bariatric surgery: systematic review. Obes 285 Surg 2012;22(1):70-89.

[10] Contreras JE, Santander C, Court I, Bravo J. Correlation between age 287 and weight loss after bariatric surgery. Obes Surg 2013;23(8):1286- 288 9.

[11] Ochner CN, Jochner MC, Caruso EA, Teixeira J, Xavier Pi- 290 Sunyer F. Effect of preoperative body mass index on weight loss 291 after obesity surgery. Surg Obes Relat Dis 2013;9(3):423-7. 292

[12] Branson R, Potoczna N, Brunotte R, et al. Impact of age, sex and 293 body mass index on outcomes at four years after gastric banding. 294 Obes Surg 2005;15(6):834-42.

[13] Herpertz S, Kielmann R, Wolf AM, Hebebrand J, Senf W. Do psy- 296 chosocial variables predict weight loss or mental health after obesity 297 surgery? A systematic review. Obes Res 2004;12(10):1554-69. 298

[14] Kinzl JF, Schrattenecker M, Traweger C, Mattesich M, Fiala M, 299 Biebl W. Psychosocial predictors of weight loss after bariatric 300 surgery. Obes Surg 2006;16(12):1609-14.

[15] Ma Y, Pagoto SL, Olendzki BC, et al. Predictors of weight status following laparoscopic gastric bypass. Obes Surg 2006;16(9):1227- 303 31.

[16] Wood GC, Benotti PN, Lee CJ, et al. Evaluation of the association 305 between preoperative clinical factors and long-term weight loss after 306 Roux-en-Y gastric bypass. JAMA Surg 2016;151(11):1056-62. 307 
[17] Ochner CN, Dambkowski CL, Yeomans BL, Teixeira J, Xavier PiSunyer F. Pre-bariatric surgery weight loss requirements and the effect of preoperative weight loss on postoperative outcome. Int $\mathrm{J}$ Obes (Lond) 2012;36(11):1380-7.

[18] Manning S, Pucci A, Carter NC, et al. Early postoperative weight loss predicts maximal weight loss after sleeve gastrectomy and Roux-en-Y gastric bypass. Surg Endosc 2015;29(6):1484-91.

[19] Wood GC, Chu X, Manney C, et al. An electronic health recordenabled obesity database. BMC Med Inform Decis Mak 2012;12:45.

[20] Jones BL, Nagin DS, Roeder K. A SAS procedure based on mixture models for estimating developmental trajectories. Sociol Methods Res 2001;29(3):374-93.

[21] Corcelles R, Boules M, Froylich D, et al. Total weight loss as the outcome measure of choice after Roux-en-Y gastric bypass. Obes Surg 2016;26(8):1794-8.

[22] Hatoum IJ, Kaplan LM. Advantages of percent weight loss as a method of reporting weight loss after Roux-en-Y gastric bypass. Obesity (Silver Spring) 2013;21(8):1519-25.
[23] Alami RS, Morton JM, Schuster R, et al. Is there a benefit to 326 preoperative weight loss in gastric bypass patients? A prospective 327 randomized trial. Surg Obes Relat Dis 2007;3(2):141-5 discussion 328 $5-6$.

[24] Brethauer S. ASMBS position statement on preoperative supervised 330 weight loss requirements. Surg Obes Relat Dis 2011;7(3):257-60. 331

[25] Mechanick JI, Youdim A, Jones DB, et al. Clinical practice guide- 332 lines for the perioperative nutritional, metabolic, and nonsurgical 333 support of the bariatric surgery patient-2013 update: cosponsored 334 by American Association of Clinical Endocrinologists, the Obesity 335 Society, and American Society for Metabolic \& Bariatric Surgery. 336 Surg Obes Relat Dis 2013;9(2):159-91.

[26] Buchwald H, Estok R, Fahrbach K, et al. Weight and type 2 diabetes 338 after bariatric surgery: systematic review and meta-analysis. Am J 339 Med 2009;122(3):248-56 e5. 